\title{
A GUINADA DA INOVAÇÃO ALIMENTAR CONTEMPORÂNEA NA FRANÇA DURANTE OS ANOS 1960*
}

\author{
The Turnaround of Contemporary Food \\ Innovation in France during the 1960s
}

Jean-Pierre Williot ${ }^{* *}$

\begin{abstract}
RESUMO
Durante a década de 1960, a alimentação dos franceses passou por um período de fortes confrontos entre tradições que se mantiveram e inovações que introduziram formas de modernidade. São estas últimas, aliás, a origem dos comportamentos alimentares atuais. Devidamente analisada por sociólogos da alimentação, esta reviravolta merece uma releitura histórica, à procura de elementos de ruptura cronológica e da dupla causa/consequência sobre um território de análise particularmente rico. Inúmeras novas tendências geram de fato práticas alimentares bastante diferentes daquelas das décadas precedentes. Vê-se, assim, donas de casa desejarem novas facilidades para fazer suas compras em função do crescimento do emprego feminino e do surgimento de novos aparelhos domésticos para simplificar seus afazeres domésticos. Ao mesmo tempo, o "comer fora de casa" tende a progredir. De uma maneira geral, a adaptação das indústrias agroalimentares à demanda de produtos mais práticos, melhor condicionados e de uso mais fácil, demonstra uma verdadeira mudança. Isto se percebe facilmente tanto no observatório do SIAL, o salão da inovação alimentar cujas primeiras reuniões começaram durante esta década, quanto nos métodos de venda dos novos circuitos de distribuição, do qual a França é campeã com a progressão dos supermercados e hipermercados. No total, é uma trans-

* Tradução Giana Cristina Coró.

** Professor de História Contemporânea, Université François Rabelais, Tours, Jean-pierre. williot@univ-tours.fr. Gostaria de agradecer particularmente a Giana Cristina Coró, titular do Mestrado em História e Cultura da Alimentação, obtido em 2009 pela Université François Rabelais de Tours, e autora de uma excelente dissertação sobre a história da sobremesa na França dos anos 1950 aos anos 2000, por ter
\end{abstract} aceitado traduzir este artigo. 
formação dos comportamentos alimentares que se opera, com nuanças entre cidades e campo, com resistência à inovação, mas mesmo assim (ainda) em uma dinâmica que faz prevalecer a diversidade alimentar e a redução generalizada da diminuição do tempo de preparo das refeições.

Palavras chave: inovação alimentar; comer fora; diversidade alimentar.

\begin{abstract}
During the 1960s, the alimentation in France went through a period of heavy clashes between traditions that have remained and innovations that have introduced forms of modernity. Those are indeed the origin of current eating behaviors. Properly analyzed by sociologists of food, this turnaround deserves a rereading of history, looking for evidence of chronological rupture and double cause and consequence of a particularly rich area for analysis. Many new trends give rise to food practices quite different from those of previous decades. Thus, it is seen housewives want new facilities to make their purchases due to the growth of female employment and new appliances to simplify their household chores. At the same time, the "eating out" tends to increase. In general, the adjustment of agri-food industries to the demand of products more practical, better conditioned and easy to use, shows a real change. This is apparent in both the observatory's SIAL, the hall of food innovation whose first meetings began during this decade, as the methods of sale of new distribution channels in which France is a champion with the progression of supermarkets and hypermarkets. Overall, it is a transformation of eating behaviors that operates with nuances between cities and countryside, with resistance to innovation, but still (still) in a process which prioritizes food diversity and the general reduction of the decrease in preparation time in meals.
\end{abstract}

Key-words:turnaround; innovation food; eating out.

Os anos 1960 são marcados por perturbações fundamentais da sociedade. Algumas alteram práticas alimentares seculares. Elas contribuem com a preparação de uma modernidade dos comportamentos, onde a inovação de produtos disputa com tradições gastronômicas antigas. Elas se inscrevem em grande parte no contexto de uma França em vias de urbanização acelerada, onde os cidadãos exercem novas demandas. É o caso em particular dos baby-boomers, que atingem a era das novas necessidades nutricionais (conta-se em 1960 32\% da população de menos de 20 anos e $26 \%$ de menos de 15 anos, dados que não tinham sido encontrados desde os 
anos $\left.1900^{1}\right)$. Inúmeras evoluções podem assim ser discernidas e este artigo se propõe a classificá-las para analisar como este período favoreceu, na França, a evolução em direção aos comportamentos alimentares contemporâneos.

É preciso, inicialmente, considerar alguns dados estatísticos:

- A população francesa aumentou em 5 milhões de habitantes em dez anos, passando de 45,1 milhões a 50,2 milhões sobre o território hexagonal. Esta é uma progressão de mais de 11\% do numero potencial de consumidores em apenas uma década. Ao nos atermos apenas aos domicílios, um milhão de lares suplementares se constituiu durante a década. Localmente, o crescimento impõe circuitos de fornecimento alimentar mais densos. Observa-se o exemplo do departamento (divisão política de região) Indre e Loire, que passa de 393.000 habitantes em 1962 a 438.000 em 19682, ou seja, exatamente a progressão nacional: $11,4 \%$ de habitantes a mais.

- Para responder a uma demanda aumentada, o aumento da produção alimentar em volume assegura a abundância. Esta última permite a passagem de um modelo alimentar fundado no aumento quantitativo das rações a uma alimentação constituída segundo critérios nutricionais ou estéticos radicalmente diferentes. Os franceses reduzem seu consumo de produtos alimentares tradicionais para ir em direção aos produtos elaborados. Esta tendência gera evoluções radicais nas indústrias agroalimentares. Ela suscita paralelamente novas exigências em matéria de condicionamento e de conservação.

- Uma alimentação mais diversificada é também possibilitada pelo decrescimento controlado dos preços alimentares ocorrido na segunda metade da década. Do índice $100 \mathrm{em} \mathrm{1960/1965,} \mathrm{os} \mathrm{preços} \mathrm{alimentares} \mathrm{baixam}$ ao índice de 94 em 1969. Somente os preços dos bens de moradia (índice 92) e das vestimentas (índice 87) caíram mais ${ }^{3}$.

- Estes fatores, conjugados à alta do poder de compra, reduzem a parte determinada à alimentação nos orçamentos domésticos, em uma década, de maneira espetacular: de 1960 a 1970, esta última perde 7,3 pontos de porcentagem (de 33,3\% a 26\%). Uma redução tal que será alcançada

1 INSEE. Annuaire Statistique de la France, 1961.

2 MITCHELL, B. R. International Historical Statistics: Europe, 1750-1988. New York: Stockton Press, 2003.

3 Economie et Statistiques, n. 123, p. 17, julho de 1980. 
novamente apenas ao final de 25 anos, de 1970 a 1994, quando a parte da alimentação chega a $18,3 \%{ }^{4}$.

\section{I-Que novas tendências influenciam as práticas alimentares?}

Três fatores afetam mais especificamente os comportamentos.

\section{A EXPRESSÃO DE NOVAS NECESSIDADES AO FAZER AS COMPRAS}

O papel do abastecimento doméstico - assim como o do preparo das refeições - ainda é tradicionalmente atribuído às donas de casa no início dos anos 1960. Mas o crescimento da taxa de atividade feminina fora de casa gera uma menor disponibilidade das mulheres a estas atividades. Na idade de 20 anos, 36\% delas são ativas em 1954, 45\% em 1962 e 50\% em 1968. Ao observarmos as taxas aos 24 anos, elas aumentam e passam a $37 \%, 47 \%$ e $53 \%$. No total, entre 1962 e 1968 , a população ativa feminina aumentou $8,2 \% ; 540.000$ mulheres se empregaram durante este período, das quais 440.000 são casadas ${ }^{5}$.

Se a aspiração à simplificação dos afazeres domésticos já se expressa durante o "entre guerras", ambos os meios de compensar o decrescimento da domesticidade e graças à oferta de uma tecnologia doméstica nova - elétrica e de gás -, a evolução do trabalho feminino requer, durante a década de 1960, novas facilidades.

A enquete publicada na revista Vendre sobre as horas de compras preferidas ou desejadas pelas donas de casa e sobre a distribuição dos produtos de compra em função do tipo de comércio em 1959 indica claramente

4 BOUQUERY, J.-M.; RENAULT, Ch. Les industries agroalimentaires. Enjeux, perspectives et stratégies des acteurs. Les Echos Etudes, 1996. Os dados variam em função das pesquisas do INSEE.

5 Economie et Statistiques, n. 26, p. 28, setembro de 1971. 
as novas necessidades ${ }^{6}$. No que concerne às horas preferidas pelas donas de casa para fazer suas compras, três pontos merecem ser extraídos:

- Assegurar o abastecimento doméstico é uma preocupação matinal: $81 \%$ das donas de casa fazem suas compras durante a manhã (das quais $55 \%$ após as 10 horas) e $37 \%$ no período da tarde (das quais $23 \%$ depois das 18 horas), em que a porcentagem total superior a 100 indica uma prática pouco eficiente de algumas donas de casa, que fazem suas compras durante a manhã e à noite. Uma diferenciação é perceptível segundo a atividade, a moradia e a renda. A atividade tende a distribuir as compras nos interstícios da jornada de trabalho: $49 \%$ das mulheres ativas efetuam suas compras após as 10 horas, contra $59 \%$ entre as não ativas; $31 \%$ das ativas deixam esta atividade para depois das 18 horas, contra $17 \%$ de mulheres inativas. A prioridade das compras a antes das 10 horas é, sobretudo, hábito das parisienses ( $21 \%$ contra $15 \%$ para as suburbanas), as donas de casa que ficam em casa $(21 \%)$ e daquelas que têm as maiores rendas (elas são $28 \%$ neste caso, enquanto que apenas $9 \%$ das categorias menos favorecidas fazem suas compras neste horário). Os modos de vida, mas também as restrições de afastamento dos estabelecimentos de comércio ou das necessidades da jornada de trabalho, fornecem elementos de explicação.

- Exprimindo seu desejo em relação à hora preferida de abertura dos estabelecimentos, as donas de casa interrogadas incitam a novas práticas comerciais: $71 \%$ entre elas gostariam que as lojas abrissem antes das 9 horas (elas são $25 \%$ a pedir a abertura das portas entre 7 e 8 horas). Para $45 \%$ das não ativas e $37 \%$ das ativas, para $42 \%$ das parisienses e $43 \%$ das suburbanas, a hora ideal para fazer as compras seria obtida pelo acesso ao comércio entre 8 e 9 horas.

- As horas de fechamento confirmam o desejo da extensão do período de abertura dos estabelecimentos: 59\% não gostariam de encontrar as portas fechadas antes da 1 hora da manhã e $57 \%$ pedem que se possa realizar as compras até as $20 \mathrm{~h} 30 \mathrm{~min}$. Esta ponderação se encontra mais acentuada entre as mulheres ativas e as suburbanas. Contudo, são pouco numerosas aquelas que imaginam uma jornada contínua sem o fechamento do meio-dia ( $6 \%$ apenas).

Alterar as horas para obter uma jornada mais extensa, mas também encontrar lojas mais de acordo com seus desejos de consumidoras indicam

6 Vendre, n. 363, maio e julho de 1960. 
tendências inovadoras. A pesquisa permite apreciar os critérios (de decisão) que dirigem então as escolhas das donas de casa. Cinco rubricas classificam as motivações de compra: preço, qualidade, escolha, serviço e ambiente. Claramente, as épiceries (mercearias) e lojas de alimentação em geral, cremeries (lojas de laticínios) independentes, as feiras, as lojas populares, os supermercados não chamam a atenção pelas mesmas razões.

- A mercearia apresenta uma grande maioria de respostas desfavoráveis sob todos os critérios, em particular para a compra de frutas e legumes e produtos lácteos. Os preços são sempre considerados muito elevados. $\mathrm{Na}$ verdade, no início dos anos 1960, a mercearia se manteve apenas em função da escolha e da qualidade das conservas. Percebe-se desde então a rápida ascensão do método Leclerc, inaugurado em Landerneau em 1949: aumentar a gama de produtos ofertados e vender mais barato?

- O mercado, enquanto estabelecimento comercial mostra-se superior em relação aos produtos frescos em todos os planos, menos no que concerne à qualidade da carne.

- Os supermercados se distinguem por apresentar um máximo de julgamentos favoráveis (possuem 22 critérios de preferência, contra 6 da mercearia e 13 da feira) em relação à carne em geral, ao serviço, ao ambiente e às frutas e legumes. Já o preço, o serviço e o ambiente são os fatores que justificam a compra da manteiga, dos ovos, queijos, café e conservas nestes estabelecimentos.

Depois desta constatação, imagina-se a possível progressão do comércio integrado e dos supermercados. Em 1969, segundo uma enquete do $\mathrm{INSEE}^{8}$, a repartição de compra de produtos alimentares operava em razão de $8 \%$ no mercado (tendência estável), $35 \%$ em um comércio independente e especializado e $24 \%$ na alimentação geral do tipo tradicional. Se já em $196565 \%$ das compras eram feitas nos "detalhistas", quatro anos mais tarde eles já tinham perdido $6 \%$ do mercado. A progressão do comércio integrado acontecia em um ritmo acelerado (22\% em 1965, 28\% em 1969). O desenvolvimento do supermercado tornava-se um fato verídico, principalmente

7 THIL, E. D'Edouard Leclerc aux supermarchés. Combat pour la distribution. Paris: Arthaud, 1964. Em particular, o ponto de vista expresso por Edouard Leclerc ao Primeiro-Ministro Michel Debré em 1959, p. 109-112.

8 INSEE, série M11, julho de 1971, p. 20. 
na alimentação geral ( $16 \%$ das compras em 1969, contra 43\% do comércio tradicional de alimentação geral), nas bebidas e laticínios (13\% cada).

Dessa maneira, em relação às demandas expressas pelas donas de casa em 1959, o desenvolvimento de novos circuitos de distribuição era uma forma de adaptação, que demonstra o surgimento de uma tendência que privilegiava as comodidades horárias, o preço e a diversidade de escolha. Apesar disso, não extrapola uma realidade que se desenhou a partir dos anos 1970, já que a estrutura da distribuição permaneceu, durante a década de 1960, largamente dominada pelos estabelecimentos de comércio tradicionais. Não houve, portanto, uma mudança radical, por mais que o número de mercados tenha crescido (1962: 207 supermercados na França, contra 2.694 en 1974) e que a invenção francesa dos hipermercados tenha balançado em apenas seis anos as estruturas comerciais antigas (Auchan foi inaugurado em Roubaix em 1961; Carrefour foi implantado em Sainte-Geneviève des Bois em 1963; 26 hipermercados em 1968).

\section{O CRESCIMENTO DA ALIMENTAÇÃO FORA DE CASA SE AFIRMA, MAS PERMANECE MARGINAL}

Um segundo sinal tangível de uma mutação das práticas alimentares nasce do desenvolvimento da alimentação fora de casa. Em 1967, uma refeição entre sete era realizada fora de casa, lembrando que no início dos anos 1990 esta proporção é de uma em três ${ }^{9}$. Em uma década, em relação aos 1990, a progressão do número de refeições feitas em cantinas triplicou e representa $30 \%$ das refeições feitas fora de casa. É importante observar que os números educacionais explicam em parte este aumento: se os escolares do ensino primário diminuíram (5,7 milhões em 1960, 5,2 em 1969), houve um aumento do número de secundaristas (passando de 1,4 milhões para 2,5 milhões). No fim dos anos 1960, 18\% das refeições foram feitas em restaurantes. Entretanto, a França não estava ainda na era do fast-food: $0,6 \%$ das refeições feitas fora de casa são na forma de refeições leves e rápidas em um café e 7,5\% são refeições transportadas em marmitas, tipo comum do trabalhador de obra e de crianças cujas mães não estão mais em casa para preparar o almoço.

9 Economie et Statistiques, n. 14, p. 51, julho de 1970. 
A refeição feita fora de casa é mais o almoço do que o jantar: $32 \%$ da população almoça fora uma vez por semana e apenas $20 \%$ janta. Além disso, se a primeira refeição se justifica por motivos profissionais, a segunda corresponde mais à atração do convívio social. Tradução do ritmo do cotidiano, o fenômeno se acentua nas grandes cidades. Assim, em Paris, $49 \%$ da população ativa faz quatro refeições em casa, enquanto que na província a taxa passa a $74 \%$. Assim, $51 \%$ de habitantes da região parisiense comem fora ao menos uma vez ao dia, enquanto que o fazem $33 \%$ dos cidadãos das cidades médias (20/200.000 habitantes) e $28 \%$ dos que residem em zona rural.

Sociologicamente, trata-se principalmente de classes superiores (69\%) e médias (62\%) que comem fora ao menos uma vez por dia. Apenas $15 \%$ dos agricultores o fazem e $32 \%$ dos artesãos. Em 1971, almoçar fora ainda era algo masculino: 9\% dos homens almoçavam em restaurantes ou em cantinas, três vezes mais que as mulheres. A mesma observação vale para os solteiros: $32 \%$ dos homens e $18 \%$ das mulheres que não eram casados não retornavam às suas casas para almoçar.

Fenômeno limitado, a alimentação fora de casa não progrediu de maneira isolada, como mostraram dois indícios.

- O crescimento do consumo das famílias, expresso em francos, gasto em hotéis, cafés, restaurantes, passa de 10,7 bilhões de francos em 1960 a 23,2 bilhões em $1968^{10}$; nas cantinas de administração e de empresas, a progressão é significativa passando de 0,6 a 1,4 bilhão.

- O fator "transporte", associado à mobilidade profissional, é um parâmetro que pesa cada vez mais na escolha do almoço no exterior: a enquete do INSEE realizada em 1967 mostra que, entre os ativos de 14 a 65 anos que têm um lugar de trabalho fixo e hábitos de transporte regulares para irem a mais de $10 \mathrm{~km}$, os franceses não são mais que $75 \%$ a almoçar em casa; passados de $20 \mathrm{~km}$, a taxa cresce a $55 \%$, e mais de $30 \mathrm{~km}: 35 \%$. Aqueles que almoçam mais em casa são os que moram em comunidades de 10.000 a 100.000 habitantes, dos quais menos de um terço não voltam para casa para almoçar. Ao inverso, os residentes das comunidades suburbanas de Paris são mais de dois terços a almoçar fora de casa. De maneira incontestável, a cidade exige novas práticas em função de uma curva demo- 
gráfica crescente. Esta tendência se inscreve nos hábitos a ponto de suscitar iniciativas apropriadas: a instauração do cheque-restaurante em 1960 e a adoção de um título-restaurante em 1967. A construção de cantinas coletivas é uma prova de que novos equipamentos de refeição coletiva foram levados em conta, introduzidos para o favorecimento da grande estandardização das refeições (fornos a vapor, fornos a convecção forçada, câmaras frias).

\section{O EQUIPAMENTO DAS CASAS PERMITE AS NOVAS PRÁTICAS CULINÁRIAS}

A modernização dos equipamentos de cozinha, surgida antes da Segunda Guerra Mundial e estendida durante os anos 1950 torna-se uma evolução característica da década de 1960 em razão de sua democratização. Certamente, diferenças persistem em função das categorias socioprofissionais e com nuanças geográficas que opõem espaços rurais e tamanho de cidades. Entretanto, a difusão de equipamentos é inegável. Ela concerne, como se sabe, o conjunto dos eletrodomésticos, mas ela é particularmente importante no que se pode chamar de "meio alimentar". Os organismos de crédito, na fase do Cetelem, fundado em 1953, contribuem fortemente. O salão das artes domésticas constitui um potente meio de propaganda. Lembrando que, em 1961, a 30. ${ }^{a}$ edição desta reunião aconteceu no CNIT, com 1.800 expositores que dividiam $80.000 \mathrm{~m}^{2}$. O concurso da fada da casa continua sendo uma atração até $1969^{11}$.

O refrigerador é o símbolo da modernidade. Este aparelho beneficia o progresso tecnológico dos fabricantes americanos, cujas marcas se impõem em cada um destes salões (geladeiras da General Motors, Kelvinator, General Electric): evaporador a serpentina que evita a dissecação dos produtos, isolamento das paredes, generalização das prateleiras, porta-objetos, iluminação interior, compartimento de baixa temperatura que permite estocar os congelados, aparição dos modelos a compressão mais baratos. Em 1960, as vendas anuais atingem 730.000 aparelhos. A progressão dos eletrodomésticos é espetacular: $24,8 \%$ das casas têm uma geladeira em fevereiro

1993.

11 ROUAUD, J. 60 ans d'arts ménagers, tome 2, 1948-1983, O consumo. Syros Alternatives, 
de 1969 e 76,9\% têm uma em janeiro de $1970^{12}$. É o maior crescimento dos produtos brancos. Certamente, a televisão penetra de forma ainda mais significativa ( 56 pontos de progressão contra 52 do refrigerador), mas ela só é encontrada em $68,6 \%$ das casas ${ }^{13}$. Certamente que diferenças persistem porque, em dezembro de $1969,62 \%$ dos assalariados agrícolas possuem um refrigerador, enquanto $95 \%$ das classes superiores o possuem. Entretanto, deve-se notar que $80 \%$ dos operários e $83 \%$ dos empregados adquirem o equipamento. As consequências no plano alimentar são numerosas: estocagem por mais tempo de produtos frescos, acondicionamento específico dos líquidos alimentares (engarrafamento cômodo dos sucos de frutas e do leite).

Outras facilidades são oferecidas às donas de casa, das quais uma grande maioria não deixa de crer que "Moulineux libera a mulher", slogan emblemático dos anos 1960, rejeitado uma década mais tarde pelos gritos do MLF (Movimento de Liberação da Mulher). Desde o salão das artes do lar de 1949, o aparelho triturador, o liquidificador, transformou-se em vedete. Ele introduz novas comodidades para cozinhar, particularmente a partir do momento em que a pesquisa dietética dos sucos de frutas e legumes torna-se aliada dos corpos femininos esbeltos à moda dos anos sessenta. Em 1964, a taxa de equipados com liquidificadores ainda varia de 10\% (assalariados agrícolas) a $63 \%$ (classes superiores, mais bem equipadas que as classes industriais e que os profissionais liberais, que ficam em 56\%). A panela de pressão (autocuisineur) se difunde, mas as taxas variam de 13\% (agricultores) a $47 \%$ (classes superiores).

Cada salão das artes do lar testemunha uma propensão à inovação, impulsionada pelas categorias sociais privilegiadas. Sinal de uma tecnologia que estava por vir, o forno micro-ondas custava 3.000 francos em $1970 !^{14}$ Ele ainda não era uma figura presente nos lares, sendo que foi preciso esperar pela década seguinte para que sua presença nas cozinhas domésticas se tornasse mais significativa, em uma transformação ou mudança real. Contudo, os salões revelam o quanto os fabricantes de equipamentos domésticos trazem mudanças sociais, particularmente urbanas, que transformam as práticas culinárias. Em 1964, o forno autolimpante da General Electric passa quase despercebido, embora tenham sido notórios os fogões mais estreitos

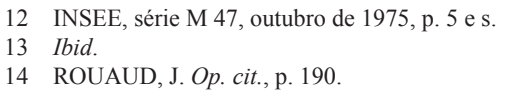


e os fornos mais volumosos. Os fabricantes equipam seus aparelhos "de novas famílias" com três fogareiros, sem grelha, pela metade do preço dos fogões aperfeiçoados (em 1968, um fogão aperfeiçoado custa cerca de 400 francos, o equivalente a um SMIG - salário mínimo).

\section{II - A adaptação das indústrias agroalimentares a esta nova sociedade testemunha deuma reviravolta profunda no mercado alimentar}

O setor ainda estava um pouco estruturado no início dos anos 1960. Marcado pela origem familiar de inúmeras empresas, durante este período de reagrupamentos e concentração este setor vê a entrada de capitais estrangeiros e crescimento global. A situação atual destas indústrias, colocadas em segundo no ranking mundial, com 138 bilhões de euros de volume de negócios, foi forjada durante estas transformações, rumo à constituição de grandes empresas. Mas convém recordar que em 1960 as indústrias da alimentação (massas, refinarias de açúcar, conservas, salgadoras, chocolaterias, doces e compotas, malte, cervejaria, produtos dietéticos e não dietéticos) somavam 6.954 empresas. A maioria delas era pequenas estruturas e contavam com uma mão de obra limitada. Por exemplo, 192 indústrias de conserva de frutas e geleias empregavam, em 1960, 5.000 pessoas; 1.045 conservadoras de carnes e salgarias remuneravam 19.000 empregados. A esta dispersão correspondia um volume de negócios fraco. As 230 empresas de massas obtinham 0,5 milhão de francos; 80 fábricas de suco de frutas e legumes chegavam a uma soma total de 24.000 francos. Estas características deram, no início dos anos 1970, a imagem de um setor fraco, disperso, de meios limitados, quando grandes reagrupamentos ocorreram. Os poderes públicos trataram desta imagem impulsionando - com uma dureza de tom revelada nos arquivos ${ }^{15}$ - a concentração e a modernização da gestão. E quer dizer que durante a década de 1960 não acontece nada? Três índices de uma relativa reatividade na indústria agroalimentar (IAA) na expressão de novas aplicações podem alterar esta percepção.

15 AN Fonds 5 AG 2, carton 1128. 


\section{NASCIMENTO DO SIAL}

O Primeiro Salão Internacional da Alimentação (SIAL) ocorreu no CNIT (Centro das Novas Indústrias e Tecnologias), de 8 a 16 de novembro de 1964. Destinado a tornar-se a vitrine das novas tendências das indústrias agroalimentares, ele se afirma com demais vocações: ser um lugar de exposição de inovação alimentar, suscitar o encontro de profissionais para confrontar a demanda social à oferta das indústrias e marcar sua notoriedade pela atribuição de preços. Suporte de inovação, o SIAL torna-se tudo isto ao reconhecer o produto alimentar francês novo, procedente de uma nova técnica, tendo obtido mais sucesso na exportação (preço oferecido com o concurso do CNCE, Centro Nacional do Comércio Exterior), o produto alimentar estrangeiro, exposto no SIAL tendo tido o máximo de sucesso durante o salão (matéria-prima que permitiu um melhor produto alimentar a partir de uma nova técnica).

O primeiro cartaz que anunciava seu aparecimento refletia as ambições do moderno, mantendo as referências tradicionais. Se o CNIT é representado como o teatro parisiense das novas manifestações, cada personagem encarnava um país e apareceu vestindo seus trajes tradicionais. $\mathrm{O}$ cozinheiro saltitante que inspira o encontro tem ainda uma sacola de compras das mais clássicas: conservas, litros de leite e garrafa de Bordeaux, pote de açúcar e salsicha etiquetada. Mas, a conotação internacional é apontada, quando necessário, através da combinação das bandeiras das Nações Unidas e da Europa. O cartaz do segundo salão, em 1966, mostra Paris, a Torre Eiffel englobando o mundo em seu ventre sobre um mapa onde os continentes compartilham uma festa agroalimentar: aves, carneiro, peixes, conservas, açúcar, biscoitos, frutas e geleias, camembert (evidentemente), mas também cerveja bock e garrafas de vinho. Uma sinalética restrita, como os prédios de vidro de uma arquitetura contemporânea, reforça ainda a preponderância parisiense para atrair os visitantes na terceira edição, em 1968. Não se trata mais, entretanto, de criar um inventário dos produtos alimentares, mas mais de afirmar o crescimento da indústria agroalimentar francesa onde acontecia o evento e onde a inovação seria percebida, na cidade capital.

O SIAL de 1966 pode servir de exemplo por caracterizar a importância do salão ${ }^{16}$. Reunidos em $40.000 \mathrm{~m}^{2}$, ele reuniu 35 países em seu 
pavilhão, 21 estandes de firmas estrangeiras, 17 estandes de importadores, representando 93 firmas estrangeiras de 25 países, produtores de 48 países. Em 9 dias foram contabilizadas 200.000 entradas, das quais 25.000 eram visitantes estrangeiros. Entre eles, 52\% vinham do Mercado Comum. E, entre os franceses, $56 \%$ residentes na região parisiense e $44 \%$ originários da província. De 100 visitantes, 28 trabalhavam no setor agroalimentar, 21 eram comerciantes de alimentação especializada, 12 representavam as indústrias fornecedoras de máquinas ou embalagens às indústrias alimentares.

As novidades apresentadas se dividem entre as que se associam ao exotismo, descobertas por novos consumidores (lichias da China, sopa de tartaruga da Tasmania, aves australianas à la gelée com sabor entre pombo e pescado, xarope de acer (Maple Syrup) do Canadá) e aquelas resultantes da criação (o chocolate savana de Brossard pasteurizado que se conserva por dois meses em sua embalagem em material próprio e sua barquete de alumínio, os champignons liofilizados, um novo pó à base de gelatina para impedir as maioneses de virarem e os soufflés murcharem). O poder dos estabilizantes e espessantes evidenciou o desenvolvimento da ciência na produção de alimentos.

Quanto à promoção da inovação, os eleitos do ano foram: os estabelecimentos Zinetti, propondo champignons liofilizados, marca Gwendalina, utilizados em aperitivos ou como acompanhamento, comercializados desde 1966; a empresa americana Uncle Bens e o arroz pré-tratado, que era apreciado por seus múltiplos atributos (qualidade de apresentação, grãos extralongos, bem separados, facilidade de emprego, arroz que não se cola, que não necessita de pré-lavagem, valor nutritivo, tudo graças a um pré-tratamento e um rendimento de $23 \%$ superior ao arroz comum). Ambos ilustram novas necessidades dos consumidores: mais que a originalidade gustativa, o que prevalece nos anos 1960 é a simplificação das práticas, a facilidade de preparação. Rapidez e comodidade tornam-se palavras-chave para a cozinha.

\section{A TRANSFORMAÇÃO DO CONDICIONAMENTO ALIMENTAR TORNA-SE UM DESAFIO ESSENCIAL}

Durante os anos 1960, inúmeras novas tecnologias são implementadas. Elas permitem a industrialização de inúmeras fabricações. Tal qual elas são apresentadas em diferentes SIALs, as várias alterações técnicas 
anunciam reviravoltas. Descobre-se a conservação por tratamento rápido a temperaturas altas; a melhoria dos produtos atomizados que não são novos, mas cujas técnicas permitem desde então tratar ingredientes que não eram trabalhados anteriormente (base de sopas, melaço de beterraba); o congelamento por azoto líquido.

Contudo, o verdadeiro sucesso da década é o desenvolvimento da liofilização. Pela desidratação dos alimentos, que impede o rompimento das células, o método consiste em congelar rapidamente a baixa temperatura; em seguida, em um vazio profundo, provocar a sublimação de sua água de constituição, ou seja, sua passagem direta do estado sólido ao qual o levamos ao estado de vapor, sem a fase líquida. A sublimação permite não causar danos às paredes celulares. As substâncias tratadas são então levadas a um estado de vida suspenso, conservando suas qualidades organolépticas, vitaminas e sais minerais. A primeira aplicação tinha sido apresentada por Arsonval e Bordas na Academia das Ciências, em 1906. Redescoberta em 1909, nos Estados Unidos, a liofilização foi aplicada, sobretudo, em domínios médicos. O custo elevado e a dificuldade técnica que representa a estabilização das passagens de temperatura e de pressão tinham retardado a aplicação no domínio alimentar. É então um grande progresso que se percebe desde que esta técnica se desenvolve finalmente. Os poderes públicos não ficam de fora, já que, favorecendo a implantação de dois projetos-pilotos (suco de frutas em Valence e champignons do vale do Maine e do Loire), o ministro Pisani dá um impulso decisivo.

$\mathrm{Na}$ outra extremidade da cadeia industrial, foi então preciso propor aos consumidores embalagens e produtos que respondessem às novas necessidades. $\mathrm{O}$ desenvolvimento dos plásticos permite a introdução no mercado de garrafas mais leves e de manuseio mais fácil. Lesieur as utiliza desde 1963 para acondicionar seus óleos de mesa. A facilidade de transporte se torna uma necessidade importante. O consumidor apaixonado pelo piquenique no campo, que por sua vez é facilitado pela automobilização da sociedade francesa, aprecia o tubo flexível de maionese. A dona de casa encarregada da família considera bastante prático o agrupamento dos potes de iogurte concebido pela Kremly, em 1965, ou a caixa de papelão Ovit, inventada em 1964 para guardar e conservar os ovos. A manipulação muda graças ao fechamento dos bocais pela tampa Twist-Off e as de conserva ao modelo Tir-Hop inventado pela Cébal (Sociedade Central de Embalagens 
de Alumínio), em 1965. Olida comercializa seus produtos com esta nova embalagem desde 1967. Uma proteção melhor resulta, enfim, da tampa plástica a partir de 1969.

Outro sinal de adaptação dos consumidores, o surgimento dos convenience foods ou produtos de consumo imediato é espetacular durante esses anos. As batatas pré-cozidas fazem ganhar tempo, como a maionese pronta que Lesieur lança em 1960. Essa orientação da indústria alimentar caracteriza o sucesso de certos produtos, pois eles respondem exatamente à demanda das donas de casa urbanas e apressadas. É o caso de Mousline, lançado em 1963. Um purê em flocos desidratados demanda apenas cinco minutos de preparação. O produto congelado ilustra também essa procura pela praticidade. O procedimento existe desde muito tempo, mas só se encarna realmente na mesa dos franceses com o nascimento de Vivagel, em 1960. O congelado ultra-rápido ou o produto resfriado limita a preparação, evita os estoques e é mais facilmente inserido nos congeladores devido ao seu condicionamento estreito. Mas a reviravolta não é apenas tecnológica. Ela ocorre igualmente na comunicação ágil sobre o consumo de produtos "mais frescos que os peixes frescos" e que não hesita a clamar: "não compre mais $70 \%$ de dejetos, compre Vivage $10 \%$ de dejetos ${ }^{17}$.

\section{A DUPLA ESTRATÉGIA DAS IAA}

Face ao mercado de massa, cuja construção se faz a partir dos anos 1960, as indústrias agroalimentares seguiram duas políticas para se adaptar.

- A primeira foi fundamentar a expansão sobre a racionalização dos métodos, a mecanização das fabricações e uma concentração que antecipava evoluções futuras. Levando em conta todas as empresas afiliadas à Federação da Alimentação, seu presidente estimava que, entre 1960 e 1967, o número havia sido reduzido pela metade, em razão de absorções e reagrupamentos. A empresa alimentar Générale, constituída em 1963, aplicava uma política de concentração horizontal baseada na retomada de marcas antigas. A fusão da Gervais e da Danone, em 1967, anunciava a constituição de um grupo

17 Museu da publicidade, Centro de documentação, dossiê temático "produtos alimentares", anúncios publicitários publicados em inúmeras fontes em 1965. 
que se apoiava em uma posição dominante (a dos produtos lácteos) que abrangia também bebidas e águas minerais desde que a BSN foi criada, em 1972. Já em 1970, as IAA conquistaram o segundo lugar no ranking industrial francês pelo volume de negócios, mesmo que a balança comercial dos produtos alimentares ainda fosse deficitária nesta data.

- A industrialização dos produtos alimentícios deu frutos em termos de mercado. O exemplo das conservas demonstra isto facilmente. A taxa de crescimento dos pratos pré-preparados e das especialidades atinge os 93\% entre 1961 e 1967 e 164\% entre 1967 e 1975; as conservas de alimentos agrícolas alcançaram índices menos elevados: $77 \%$ e 69\%. Fabricaram-se na França 71.000 toneladas de pratos pré-preparados em 1961, 137.000 toneladas em 1967, 363.000 toneladas em 1975, ou seja, cerca de 1,5 kg por habitante em 1961 e mais de $2,5 \mathrm{~kg}$ em $1967^{18}$. As evoluções sociais apresentadas no início se refletem nestas alterações de consumo.

Consequência evidente deste desenvolvimento do mercado alimentar, as indústrias adotaram novas estratégias de comunicação destinadas ao consumidor. O impacto publicitário não foi uma novidade: basta analisar os cartazes em cores dos artistas da Belle Epoque enaltecendo os méritos de inúmeros produtos. O que se dá na década de 1960 é um grande crescimento do fenômeno de comunicação. As campanhas se tornam pluridimensionais, aliando encartes publicitários em revistas femininas, cuja variedade cresce, em ações que englobam artigos promocionais, receitas e apresentação de pratos e que têm os slogans rapidamente memorizados por intermédio do rádio e da televisão desde 1968. Os produtos alimentares invadem a mídia nas cidades, mas também em regiões rurais, onde o consumo se aproxima ao dos centros urbanos graças à homogeneização dos comportamentos, que a televisão favorece, e atingem tanto famílias tradicionais quando os jovens, que prescrevem novos gostos.

Uma marca antiga como a Liebig, de métodos comprovados e de certa notoriedade, pode servir como exemplo desta solicitação permanente do consumidor. Um artigo publicado na revista Vendre ("Vender") demonstra a adaptação a estratégias inovadoras: implementação do merchandising, em 1963, baseado na atratividade de mercadorias expostas de maneira agressiva, estabelecendo uma relação entre a publicidade e a venda; criação de

18 MERCIER, M-A. La consommation alimentaire en 1977. Les collections de l'INSEE, série M, Ménages, n. 83. 
um sistema de ciclos promocionais baseados em ofertas particulares aos detalhistas e reduções excepcionais aos consumidores ${ }^{19}$. Outros apostam na comunicação de massa, como campanhas promocionais de conserva de ervilhas com o slogan inesquecível, ou ao menos memorável, "sempre se precisa de ervilha em casa". Mas, a ambição ainda é algumas vezes modesta, quando, por exemplo, em uma mensagem divulgada por rádio, as conservas William Saurin prometem um lote de conservas às recém-casadas. A abundância ainda não era generalizada.

A inovação é um meio de mobilizar o consumidor. A indústria usa e abusa deste quesito durante a década, segundo três tendências:

Uma identificação das marcas com a ajuda de uma sinalética mais distintiva (os três filets bleus, produto da marca da Danone, que passam aos potes termoformados) ou pelo lançamento de uma novidade: em 1967, Yoplait lança os petits suisses "flor azul", cujos potes plásticos, dispostos em estrelas e selados entre si como as pétalas de uma flor, permitem tanto uma diferenciação em relação às outras marcas como ganham a aprovação dos compradores graças ao acondicionamento inteligente. As vendas aumentam em 200\% em um ano e Yoplait ganha o Oscar da embalagem.

Considerou-se, igualmente, o desafio de mercado que a clientela jovem representa. A inserção de presentes também incita à compra (bandeiras da Alsace, ioiô da Banania). A evolução das embalagens familiares e a individualização das porções são outras formas de resposta (1960, o café solúvel Nescafé em embalagens individuais; 1961 BN em pacote familiar e, em 1963, em embalagem sanfonada).

A ideia era propor a diversidade, enfim, como uma prova de que a contribuição quantitativa não primava mais. O que contou, desde então, foi a apropriação pelo consumidor de uma capacidade de arbitragem qualitativa, as fontes de uma diversificação rápida das escolhas e de uma rotação dos produtos acelerada na grande distribuição (cujo sucesso se devia justamente graças às novas exigências). Por exemplo, a Danone criou 5 tipos de iogurte em 7 anos: a éclair (semelhante à bomba brasileira) (1960), o iogurte natural aveludado (1963), o iogurte de frutas (1964), o Dany gelificado (1966) e o aveludado de frutas e liégeois (de Liège, 1967). 


\section{III - A transição dos comportamentos alimentares}

Como resultado das evoluções estruturais dos anos 1960, as práticas alimentares dos franceses lançaram novas tendências que são confirmadas nas décadas seguintes. Mas, isto não descarta as diferenças sociológicas que impedem qualquer globalização ${ }^{20}$. As práticas alimentares continuam como um fator discriminante da situação social, mesmo depois de uma década de crescimento. As reações dos consumidores à inovação, e mais particularmente a das donas de casa responsáveis pela mesa da família, não têm nada de uniforme. $\mathrm{O}$ cruzamento de inúmeros parâmetros constitui tantas variáveis que, em uma determinada época, jogam de forma cumulativa ou contraditória, algumas vezes de maneira muito mínima, em função de arbitragens pessoais. O que têm em comum uma mãe de várias crianças que vive no campo e uma jovem secretária que vive solteira em um estúdio parisiense? Entretanto, também não se pode descartar o fato do surgimento de um novo modelo nutricional, uma nova definição de prazer alimentar, tendo sido elaborado em um contexto urbano que anunciava cada vez mais a modernidade.

\section{A ESTRUTURA DO CONSUMO}

Em valores, a evolução do consumo das famílias passa de 64,8 bilhões de francos da época (1960) a 109,2 (1968) $)^{21}$. Por categoria, os produtos cereais têm "peso" idêntico (12\%); já o custo das bebidas cai (de $18,7 \%$ a $16,3 \%$ ) e o da carne cresce (de $34 \%$ a $36,8 \%$ ), sinal tanto de um aumento no consumo como do aumento de certos preços. O fenômeno afeta todos os tipos de carne: gado (de 5 a 9 bilhões), vitela (2 a 3,5), carneiro (de 0,7 a 1,4) e até mesmo coelho e carnes de caça (de 1 a 2,5). O mesmo se dá para os embutidos (de 4,5 bilhões a 9,2). Os crustáceos triplicam seu valor de consumo, os produtos lácteos dobram. Contando que o conjunto açúcar/doces/chocolate passa de 2,2 a 4 bilhões, pode-se resumir que os franceses dos anos 1960 comem de forma cada vez mais "rica", pelo gasto

20 POULAIN, J-P. Sociologies de l'alimentation. Reedição da primeira edição de 2002. Paris: PUF, 2007, p.184 e s.

21 INSEE, coleção M 3, agosto de 1970, tableaux, p. 20 e s. 
que eles têm (mesmo se o valor relativo pesa menos nas despesas gerais de orçamentos domésticos) e pelas calorias que eles absorvem.

Em 1969, o consumo domiciliar médio se distribui da seguinte maneira $^{22}$ : carnes, aves e peixes: $39,2 \%$; bebidas: $13,7 \%$; legumes: $10,7 \%$; produtos à base de cereais: $10 \%$; produtos lácteos: $9,7 \%$; frutas: $6,8 \%$; gorduras: $6,3 \%$; diversos: $3,6 \%$.

Pode-se assim perceber evoluções que refletem uma mutação dos hábitos:

- A taxa de consumo dos congelados em $\mathrm{kg} /$ habitante mostra uma rápida evolução, passando de 0,2 em 1961 para 1,2 em 1967, mas em valores eles representam ainda um mercado restrito: 53 milhões de francos em 1960, 114 em 1968;

- Os alcoólicos ditos de "convívio" mostram uma nova "sociabilidade": o champanhe e os aperitivos triplicam em valor, e as aguardentes dobram;

- O crescimento das bebidas destinadas aos jovens (suco de fruta, bebidas com gás, xaropes) se afirma, marcando a atmosfera dos sixties: 167 milhões de francos em 1960, meio bilhão em 1968. Já o consumo de leite por esta classe cai cada vez mais, como o dos franceses em geral: 86 litros por ano por pessoa em 1965 e 80 em 1969.

Apesar de um claro processo de unificação, as tendências não excluem as diferenças sociais, que ainda aparecem em 1969:

- Entre um operário qualificado ou o assalariado agrícola, o patrão industrial ou um profissional liberal, o orçamento anual por pessoa passa de 1.600 francos a 2.500;

- Na estrutura do consumo, a carne continua sendo símbolo de poder aquisitivo, porque ela, entre as categorias socioprofissionais, representa de 38 a $43 \%$ da estrutura alimentar.

\section{RESISTÊNCIAS E ACEITAÇÕES QUANTO À INOVAÇÃO ALIMENTAR}

Assim como se percebe na revista Indústrias Alimentares e Agrícolas, o discurso científico dos anos 1960 renova os conhecimentos 
nutricionais. A importância dos aportes proteicos é ressaltada. Isolando as proteínas das leveduras, dos peixes, dos grãos, das algas, os biólogos apresentam uma alimentação muito mais complexa. Uma melhor compreensão das qualidades lipídicas contribui para dissociar a opinião científica dos preconceitos tradicionais. Afirma-se, dessa forma, que a superioridade dietética da manteiga, ancorada na memória culinária, nada tem de verídica. A indústria rapidamente toma partido: em 1969, Fruidor e Auréa introduzem novas práticas. O conhecimento mais elaborado, porém, não evita o debate. É o caso dos corantes e aditivos sintéticos, cuja inocuidade não está provada.

Falando naa abertura do SIAL de novembro de 1966, Michel Cointat (diretor-geral da Produção e das Feiras no Ministério da Agricultura) percebeu a presença de um ambiente incerto:

Existem produtos parcialmente sintéticos como as leveduras de petróleo ou o queijo extraído da farinha de peixe, produtos puramente sintéticos - que são um pouco inquietantes - como, por exemplo, os ciclamatos destinados a substituir o açúcar [...] Eu não gostaria de concluir sem vos suplicar de serem extremamente prudentes face a esta evolução da alimentação. Falta de precaução, arrisca-se de romper o equilíbrio frágil e a harmonia instável da vida. Nossas atitudes neste domínio podem reduzir reações extremamente prejudiciais ao ser vivo. Nesta área, a mesa familiar tem, de alguma maneira, um papel e um valor simbólico de que a gastronomia é guardiã da civilização ${ }^{23}$.

Falando nisso, aliás, como as donas de casa percebem esta transformação rápida da alimentação? Uma enquete publicada em 1969 responde a esta questão de maneira circunstancial ${ }^{24}$ :

- No mínimo $60 \%$ delas utilizam alimentos industrializados, sobretudo quando se trata de sobremesas, congelados e iogurtes com sabor. Entretanto, uma diferença deve ser observada quanto ao local onde moram. Por exemplo, uma distância de 30 pontos pode haver quanto ao consumo de sopas de pacote, de maionese em tubo e de purê desidratado entre as grandes cidades e a zona rural. Assim, $40 \%$ das donas de casa utilizam o purê do

23 Revue IAA, 84 e ano, n. 2, p. 120, fevereiro de 1967.

24 SERVILLE, Y. Attitude de la ménagère devant les produits alimentaires proposés par l'industrie. Indústrias Alimentares e Agricolas, janeiro de 1969, p. 135 e s. 
tipo Mousline nas grandes cidades, $20 \%$ nas pequenas cidades e $10 \%$ no campo, onde a batata é frequentemente produzida no jardim da proximidade;

- De uma maneira geral, a taxa de utilização é muito mais baixa (menos de 30\%) para o consumo de morangos congelados (continua-se a comer conforme a estação), de massas industriais para a confeitaria (o processo caseiro de associação da farinha, manteiga e ovos continua sendo privilégio da cozinheira e uma propedêutica gastronômica para as netas), as carnes congeladas (o corte pelo açougueiro continua sendo uma forma de controle da qualidade);

- É surpreendente, entretanto, o baixo emprego de pratos pré-preparados ( $9 \%$ das donas de casa admitem utilizá-los), mesmo que a indústria dele se desenvolva significativamente;

- Ao contrário disto, a correlação entre a taxa de atividade máxima das mulheres (entre 30 e 50 anos), o número de crianças (nas famílias com mais de 3 crianças) e a porcentagem de utilização da produção industrial encontra sua razão de ser pela procura pela facilidade de preparo.

Mesmo que sejam confrontados dois modelos culinários, a dona de casa que utiliza estes produtos novos e a que continua tradicional, argumentos permitem a análise das razões da aceitação da inovação.

Entre as que utilizam, $32 \%$ declaram que o fazem pela praticidade que esses produtos oferecem. Facilidade de uso, rapidez de preparação, eliminação do serviço de descascar prevalecem. Mas, o modo de vida circunstancial contribui também para esta tendência. O camping também é apresentado como um motivo para a utilização dos recursos industriais, as sopas em pacote e as sobremesas ficando em primeiro lugar no ranking. O gosto bom, citado por $28 \%$ das pessoas interrogadas, só vale para as sobremesas e os iogurtes, sendo uma demanda principalmente das crianças e adolescentes. Aliás, $21 \%$ das mães desconfiam do julgamento das avós e aceitam o "gosto bom" dos iogurtes aromatizados. Elas reconhecem que outros produtos, como a maionese em tubo e, sobretudo, o café solúvel têm gosto ruim: apenas $12 \%$ apreciam estas comodidades, $30 \%$ dizem que o café não é bom. O preço não é argumento significativo no que concerne aos peixes congelados, aos molhos e às massas prontas. As donas de casa que são clientes da indústria agroalimentar não temem uma desnaturação da qualidade ou qualquer risco alimentar. Apenas $7 \%$ das donas de casa afirmam desconfiar ou mesmo ter medo destes produtos. 
Considerando o ponto de vista daquelas que se encontram no grupo de "não utilizadoras" destes produtos, é precisamente a desconfiança o fator principal da precaução. De $30 \%$ a $70 \%$ delas se declaram hostis quanto aos produtos. Logicamente, recusam os industrializados considerando a importância de controlar o abastecimento doméstico: 70\% desconfiam das massas prontas, $62 \%$ da maionese em pote, $59 \%$ não confiam nas sobremesas. O gosto ruim vem em segundo plano, mas é o principal argumento de recusa do café solúvel (47\%). A taxa de respostas negativas a certas questões prova que estas donas de casa não se sentem seduzidas, dizem elas, porque a novidade não é atraente, a publicidade não tem impacto e a tradição vem se mostrando superior. De maneira geral, se estes produtos são recusados é pelo argumento da desconfiança, por serem "maus para a saúde", "não naturais", "não frescos". Finalmente, elas preferem fazer "elas mesmas". Com este argumento, prevalece a recusa de um alimento que não é personalizado. Já em 1959, o órgão dos pequenos comerciantes em luta contra os supermercados declarava se opor "aos fanáticos que querem enfim que todos os franceses comam o mesmo cardápio, na mesma hora, $\mathrm{e}$ no mesmo dia [...] quando todos comerão a mesma marmita da mesma cantina" ${ }^{25}$. Nos aproximamos simultaneamente da ideia da indústria alimentar que prepara seus produtos, sem escrúpulos, à base de gêneros de origem duvidosa, através de métodos químicos que impedem ao produto a virtude de ser natural. Discurso de recusa à inovação ao qual se opõem os adeptos da química alimentar, convencidos, nesta mesma época, de que a indústria pode englobar a qualidade. Compondo o SIAL de 1966, Marcel Loncin, professor de Engenharia Alimentar em Bruxelas, conselheiro científico da ENSIA (Escola Nacional Superior das Indústrias Agroalimentares), em Massy, promove o produto industrializado a partir do momento em que declara: "Está-se cada vez menos certo de que um produto natural e não transformado é superior a um produto submetido a tratamento industrial. Da mesma forma que estamos cada vez menos certos de que um tratamento adicional como o defumado não apresenta nenhum perigo à saúde apenas por já ser praticado há bastante tempo!'26.

25 La volonté du commerce et de l'industrie, organismos de PME, maio de 1959.

26 Revue $I A A, 84^{\mathrm{e}}$ ano, n. 2, fevereiro de 1967. 


\section{SLOGANS DA MODERNIDADE}

Face à reticente opinião pública perfeitamente consciente de que estava vivendo um período de mudanças durante estes anos, três vias traçam perspectivas às indústrias agroalimentares para modificar os comportamentos.

O discurso da mídia contribui fortemente para a promoção da inovação, mas as intenções são variadas. Quando a revista Elle publica, em 1966, uma enquete sobre os produtos $\operatorname{congelados}^{27}$, o texto destaca o avanço americano (prova de modernidade), a qualidade da conservação (na perspectiva tecnófila liberal) e a destruição dos ciclos sazonais obrigatórios (uma abordagem libertadora). Mostram-se as experiências de consumidoras pioneiras. Faz-se referência, neste caso, às cooperativas rurais, em lugar das grandes cidades. Por exemplo, as cooperativas de congelamento, como a Combalouzet, na pequena cidade de Aveyron, rebatizada como "kolhoze do frio", ou de outra instalada em Saint Himaile du Harcouët, endereço secular de 4.000 habitantes, de forte influência normanda e das feiras tão aclamadas. Poderíamos citar ainda o vanguardismo da trintona suburbana que usa seu tempo à maneira americana, dispondo em sua casa de Bièvres, comunidade de 2.900 habitantes, de um congelador individual Radiola de 265 litros por 2.295 francos ( 7 vezes o valor do salário mínimo). Para ela, a publicidade televisiva é marcante pela novidade. O objetivo não é exatamente a descrição técnica da novidade, mas sim conquistar um mercado de massa. É necessário atrair o telespectador de forma tão persuasiva que ele se torna fiel facilmente. As armas de Gervais e do chocolate Lanvin não ficam para trás. $\mathrm{O}$ ator Jacques Duby interpreta, vende os méritos de Boursin utilizando sua "arte declamatória". A mídia é também vetor de tendências comportamentais, dando o tom: o exotismo do consumo de palmito e de abacate, por exemplo.

Outra estratégia surge da promoção da qualidade. Em 1960, o selo Label vermelho promove os produtores que desejam se distinguir das filiais industriais. Quando os criadores de aves de Loué obtiveram o precioso título, em 1966, foi exatamente para se diferenciarem dos criadores da Bretagna, que se lançaram nesta corrida da criação feita em gaiolas em bateria. Dois 
modos de agricultura se opõem antes de tornarem-se emblemas de escolhas alimentares seletivas. A resposta rápida à chegada das filiais produtivistas se apresenta. Mais alguns anos e a origem campestre dos alimentos encontraria a preferência dos cidadãos urbanos à procura de novidades sob o disfarce do discurso de terroir, receita mágica para atrair o consumidor nostálgico.

A promoção de uma nova estética é rapidamente associada às novas tendências alimentares. No final dos anos 1960, as medidas femininas ideais (ou idealizadas) favorecem os corpos magros. Quanto ao homem, é o conjunto dinâmico, alerta e flexível (mas também sobrecarregado) que é representado nas propagandas publicitárias. As indústrias agroalimentares inscrevem suas inovações e seus discursos neste modelo urbano, onde Sveltesse e Badoît formam a dupla, o casal in.

Resumindo, os anos 1960 representam tempos privilegiados por uma mutação que associa a dualidade de referências que projetam a "idade de ouro" no passado e do futuro. As primeiras estendem-se no campo semântico do autêntico (o virgem, puro e são), do gosto personalizado e de um tempo antigo, sinônimo de confiança e de segurança ao qual se opõem a simbólica do químico, traduzido pelo impuro, a alteração do natural, a insipidez que engloba a inquietude e a frustração gastronômica. Os segundos remetem, ao contrário, à critica do empírico e do bruto, rústico, face ao progresso da higiene e do refinamento. O ganho de tempo é valorizado, ao invés da servidão. São duas Franças que se afrontam. Por um lado, aquela do campo e, por outro, a das cidades. A cidade é consumidora das inovações que a indústria agroalimentar permite. Mas o cidadão vive também de nostalgia, hesitando entre a comodidade técnica e a procura pelo sabor. Deste ponto de vista, os anos 1960 traduzem esta contradição que não parou mais de crescer.

Recebido em agosto de 2010. Aprovado em agosto de 2010. 